\title{
Implementasi Framework Laravel Pada Sistem Informasi Pengelolaan Aset Laboratorium Komputer
}

\author{
Muhammad Iqbal Awaluddin ${ }^{1}$, Rita Wahyuni Arifin ${ }^{1, *}$, Didik Setiyadi $^{2}$ \\ $1,1^{*}$ Manajemen Informatika; Universitas Bina Insani; Jl. Siliwangi No.6 Rawa Panjang Bekasi \\ Bekasi Timur 17114 Indonesia, Telp. (021) 82436886 / (021) 82436 996; e-mail: \\ muh.iqbal625@gmail.com, ritawahyuni@binainsani.ac.id
}
${ }^{2}$ Teknik Informatika; Universitas Bina Insani; Jl. Siliwangi No.6 Rawa Panjang Bekasi Bekasi Timur 17114 Indonesia, Telp. (021) 82436886 / (021) 82436 996; e-mail: didiksetiyadi@binainsani.ac.id
* Korespondensi: e-mail: ritawahyuni@binainsani.ac.id

Diterima: 23 Nopember 2020; Review: 07 Desember 2020; Disetujui: 21 Desember 2020

Cara sitasi: Awaluddin MI, Arifin RW, Setiyadi D. 2020. Implementasi Framework Laravel pada Sistem Informasi Pengelolaan Aset Laboratorium Komputer. Bina Insani ICT Journal. 7(2): 187197.

\begin{abstract}
Abstrak: Laboratorium merupakan salah satu prasarana pendidikan yang perlu tersedia mulai dari tingkat menengah atas hingga perguruan tinggi. berupa ruangan untuk melakukan pembelajaran berbasis praktikum. Peralatan yang ada pada laboratorium bisa saja sangat banyak, dan tidak terdata dengan baik maka diperlukan suatu pengelolaan yang bisa memberikan informasi peralatan apa saja yang ada dan yang dibutuhkan setiap laboran. Pengelolaan ini berguna untuk menampilkan data peralatan yang ada. Melihat masalah yang ada dengan ide yaitu membangun suatu sistem pengelolaan aset yang terdapat pada Laboratorium berbasis web yang dapat mengelola pendataan perangkat serta peminjaman terhadap perangkat alat-alat praktikum jaringan Universitas Bina Insani. Metode pengembangan yang digunakan dalam pembuatan aplikasi ini adalah metodologi Rapid Application Development (RAD). Tahapannya terdiri dari perencanaan syarat-syarat, Workshop Desain RAD, serta implementation. Bahasa pemrograman yang akan digunakan adalah Hypertext Prepocessor (PHP) dengan framework Laravel. Untuk tampilan web menggunakan framework Cascading Style Sheet (CSS) bootstarp. Perancangan database menggunakan adalah MySQL. Kesimpulannya adalah adanya sistem informasi untuk manajemen dalam aset yang dapat memberikan informasi antara jumlah barang yang berada pada laboratorium dengan catatan yang tersimpan yang akan lebih akurat, proses pencatatan akan menjadi rapih dan mengurangi terjadinya kehilangan data karena data tersimpan dalam bentuk file, mencari data akan jauh lebih efektif dan efisien, pemanfaatan framework laravel dapat memudahkan bagi admin dalam mengelola aplikasi dengan mudah.
\end{abstract}

Kata kunci: laboratorium, laravel, pengolalaan aset, sistem, website.

Abstract: The laboratory is one of the infrastructures that need to exist in the field of education starting from high school to higher education. in the form of a room for practicum-based learning. There can be a lot of equipment in the laboratory, and it is not well recorded, so a management is needed that can provide information on what equipment is there and what is needed by each laboratory assistant. This management is useful for displaying existing equipment data. Seeing this problem, an idea emerged, namely to build an asset management system contained in a web-based laboratory that can manage data collection on devices as well as lending to the Bina Insani University network practicum tools. The development method used in making this application is the RAD (Rapid Application Development) methodology. The stages consist of planning requirements, RAD Design Worksop, and implementation. The programming language to be used is the Hypertext Prepocessor (PHP) with the Laravel framework. For web display using Bootstarp Cascading Style Sheet (CSS) framework. Database design using is MySQL. The expected result of this research is that there is an asset 
management information system that can provide information between the number of items in the laboratory and stored records that will be more accurate, the recording process will be neat and reduce the occurrence of data loss because the data is stored in the form of files, searching for data will be much more effective and efficient, utilization of the laravel framework can make it easier for admins to manage applications easily.

Keywords: laboratory, asset management, laravel, system, website.

\section{Pendahuluan}

Dalam Permendikbud No. 3 Tahun 2020 tentang Standar Pendidikan Tinggi dalam pasal 33 tertuang bahwa adanya standar sarana untuk pembelajaran yang diperlukan dengan penyediaan Laboratorium. Dalam dunia pendidikan pada setiap tingkat baik itu dari tingkatan dasar sampai dengan tingkatan perguruan tinggi fasilitas laboratorium komputer merupakan sarana yang sangat dibutuhkan dalam mendukung proses pembelajaran [1]. Laboratorium adalah tempat yang digunakan untuk kegiatan mengembangkan kegiatan teknologi informasi [2]. Aktivitas yang terjadi di dalam laboratorium komputer mulai dari pencatatan barang yang masuk ke dalam laboratorium, peminjaman alat atau perangkat keras yang berada pada laboratorium, pengembalian alat laboratorium yang telah selesai di pinjam hingga pelaporan mengenai data-data laboratorium komputer. Dalam memantau kemajuan segala aktivitas di dalam laboratorium diperlukan pendataan dan pencatatan atau biasa dikenal dengan kegiatan administrasi. Pemanfaatan teknologi seperti ini akan memudahkan dalam melakukan pengelolaan administrasi [1].

Berdasarkan pengalaman penulis saat menjadi tenaga laboran disebuah sekolah menengah kejuruan bahwa proses pencataan dan pendataan barang atau perangkat keras serta peminjaman dan pengembalian alat atau perangkat keras milik laboratorium hingga pelaporan masih menggunakan sistem secara manual. Kegiatan pengelolaan barang masih menggunakan pencatatan secara manual kemudian disimpan dan dicatat kembali pada aplikasi Microsoft excel. Sedangkan catatan peminjaman dilakukan dalam bentuk catatan tertulis. Proses peminjaman maupun pengembalian barang di lakukan secara tertulis sehingga yang terjadi adalah ketidaksesuaian data asli yang berada pada laboratorium komputer dengan data yang tertulis baik itu dalam buku catatan maupun yang berada pada Microsoft excel. "Sistem diartikan secara sederhana merupakan suatu kumpulan atau himpunan yang berisi elemen, variable yang terorganisasi, yang saling berinteraksi, memiliki ketergantung satu sama lain, dan terpadu" [3]. Sistem Informasi adalah perpaduan antara aturan kerja, data yang sudah diolah, manusia dan information technology dalam mewujudkan tujuan organisasi [4].

Dalam jurnal ini penulis menggunakan beberapa sumber referensi dari penulis lain yaitu Trisnanto dan Lala berdasarkan hasil penelitiannya menyatakan bahwa dengan sistem informasi laboratorium dapat mengelola data kegiatan laboratorium komputer dengan secara cepat dan akurat, kemudian mampu menyimpan data mahasiswa setiap kali mengikuti kegiatan praktikum, dengan sistem informasi laboratorim dapat menghasilkan laporan data mahasiswa, tugas, modul dan jumlah pengajar dalam laboratorium dengan secara akurat dan cepat [2].

Laravel adalah framework yang menerapkan Konsep MVC (Model-View-Controller) [5]. Dalam konsep MVC (Model-View-Controler) untuk model berisi coding untuk pengelolaan basis data tetapi tidak berkonektivitas dengan view yang merupakan file dalam script pada HTML, sedangkan controller adalah penghubung view dan model [6].

PHP digunakan dalam membuat antarmuka web yang tidak statis dimana kode-kode PHP disisipkan diantara kode HTML [7], serta MySQL sebagai bahasa query yang akan digunakan untuk pengelolaan basis data [8]. Dengan adanya implementasi framework Laravel dalam sistem ini sebagai sistem baru dapat meminimalisir terjadinya ketidaksesuaian antara jumlah barang yang berada pada laboratorium dengan yang dicatat dan disimpan, merapihkan catatan serta prosesnya, dan proses pencarian serta dan pembuatan laporan tentang pengelolaan aset pada laboratorium lebih mudah, efektif dan efisien. Dalam desain sistem ini, penulis menggunakan pemodelan perangkat lunak untuk memberikan kemudahan dalam pengembangan aplikasi agar lebih terencana dan bentuk pemodelan UML dan diagram yang digunakan adalah Usecase, Scenario Usecase, Activity dan Class Diagram [9]. Tujuan Penelitian adalah untuk menghasilkan sistem informasi untuk manajemen mengenai aset di laboratorium komputer dari sistem manual ke dalam sistem berbasis web. Manfaat dalam pembuatan sistem informasi ini adalah dapat memenuhi kebutuhan pengelolaan aset 
laboratorium komputer pada perguruan tinggi lebih berkualitas dari sistem yang sudah ada. Untuk mempermudah proses pencatatan barang serta pengelolaannya, dalam pencarian data baik itu data barang ataupun yang lainnya dan dalam pembuatan laporan mengenai pengelolaan aset sangat dibutuhkan sebuah sistem pengelolaan aset laboratorium komputer yang terkomputerisasi dengan menggunakan bahasa pemrograman PHP dengan framework Laravel.

\section{Metode Penelitian}

Pengembangan sistem yang digunakan adalah model RAD [10] adalah metode yang digunakan dalam pengembangan perangkat lunak tambahan dimana siklus pengembangannya relative singkat [11]. Pada Model ini terdapat tahapan- tahapannya pada gambar 1, antara lain: 1). Requirements Planning, melakukan pertemuan dengan narasumber untuk membahas mengenai sistem yang dibangun guna membahas tentang tujuan dari sistem dan kebutuhan informasi untuk mencapai tujuan. Dalam tahapan ini juga dilakukan pengumpulan dan analisis alat, bahan, sumber daya, biaya dan data; 2) RAD Desain Workshop, Tahapan ini dilakukan proses desain dan melakukan proses perbaikan apabila masih tidak sesuai dengan user, desain sistem mengacu pada hasil dari tahapan sebelumnya; 3). Implementation, pada tahapan ini programmer melakukan pembangunan sistem dengan melkukan coding [12], sebelum sistem tersebut diimplementasikan dalam suatu organisasi terlebih dahulu dilakukan testing dan user memberikan tanggapan secara langsung terhadap aplikasi tersebut

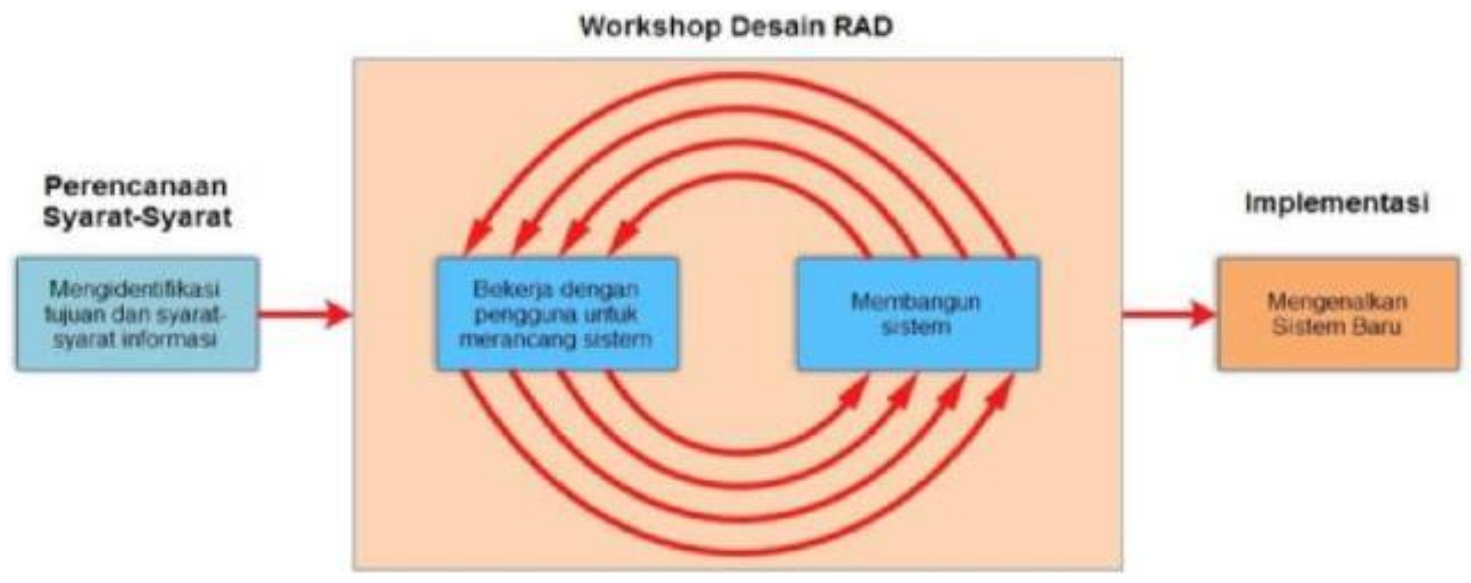

Sumber: Kendall (2010)

Gambar 1. Metode Pengembangan RAD

Teknik dakam mengumpulkan data dalam penelitian adalah: 1) Observasi, observasi dilakukan dengan mengamati secara langsung kegiatan peminjaman barang milik laboratorium serta langkah-langkah pengembalian barang milik laboratorium yang sudah berjalan pada Universitas Bina Insani yang beralamat di Jln. Raya Siliwangi No. 6 Rawa Panjang Kota Bekasi. Hasil observasi adalah data primer dan gambaran sistem yang dibutuhkan, 2). Wawancara, kegiatan wawancara dilakukan untuk memperoleh data primer yang belum didapatkan oleh dari tahapan observasi. Hasil wawancara bukan hanya berupa data primer, tetapi dapat berupa data sekunder serta jalannya alur proses peminjaman dan pengembalian barang milik laboratorium untuk mendapat gambaran terkait sistem yang akan dibangun. Pihak yang diwawancara adalah kepala laboratorium Universitas Bina Insani yaitu Bpk. Jafar Shadiq dan Bpk. Mardi Yudhi Putra, dan 3) Studi Pustaka dengan mempelajari dan mengumpulkan informasi melalui bukubuku, jurnal terkait dan internet. Berdasarkan dari penjelasan diatas maka penulis membuat diagram dan alur berjalannya sebuah penelitian yang dibuat berdasarkan penelitian yang sedang dilakukan.

\section{Hasil dan Pembahasan}

Berdasarkan hasil pengamatan dan penelitian yang dilakukan oleh penulis maka hasil dan pembahasannya adalah sebagai berikut:

Perencanaan Syarat-syarat, pada tahapan ini dilakukannya pertemuan secara langsung dengan narasumber yaitu kepala laboratorium pada Universitas Bina Insani dan dilakukan 
wawancara berupa tanya jawab mengenai hal-hal yang menyangkut dalam pembangunan sistem ini serta melakukan observasi guna melakukan survei lapangan dan studi pustaka untuk mengumpulkan data sekunder untuk membantu dalam pengembangan sistem informasi serta melakukan analisa keperluan perangkat keras dan lunak. Kebutuhan hardware merupakan media pendukung untuk membuat dan menjalankan sebuah aplikasi berbasis web. Berikut ini adalah kebutuhan yang diperlukan untuk membuat dan menjalankan sebuah aplikasi

Tabel 1. Kebutuhan Hardware untuk develop dan menjalankan aplikasi

\begin{tabular}{ll} 
Kebutuhan Hardware development aplikasi & Kebutuhan Hardware Untuk Menjalankan Aplikasi \\
\hline Processor AMD A8 PRO 1.9GHz & Processor merk Intel Core 2 Duo \\
\hline Memory 8GB & Memori 4 GB \\
\hline VGA 4GB & VGA 1 GB \\
\hline SSD 240 GB & Harddisk 512 GB \\
\hline
\end{tabular}

Sumber: Hasil Penelitian (2020)

Kebutuhan Software adalah Perangkat Lunak terdiri dari dua jenis, diantaranya: software untuk sistem dan aplikasi. Perangkat lunak sistem diperlukan untuk menjalankan tugas-tugas dasar tertentu yang diperlukan semua pemakai komputer, sedangkan perangkat lunak aplikasi dipakai untuk memproses data aplikasi pada gambar 2.

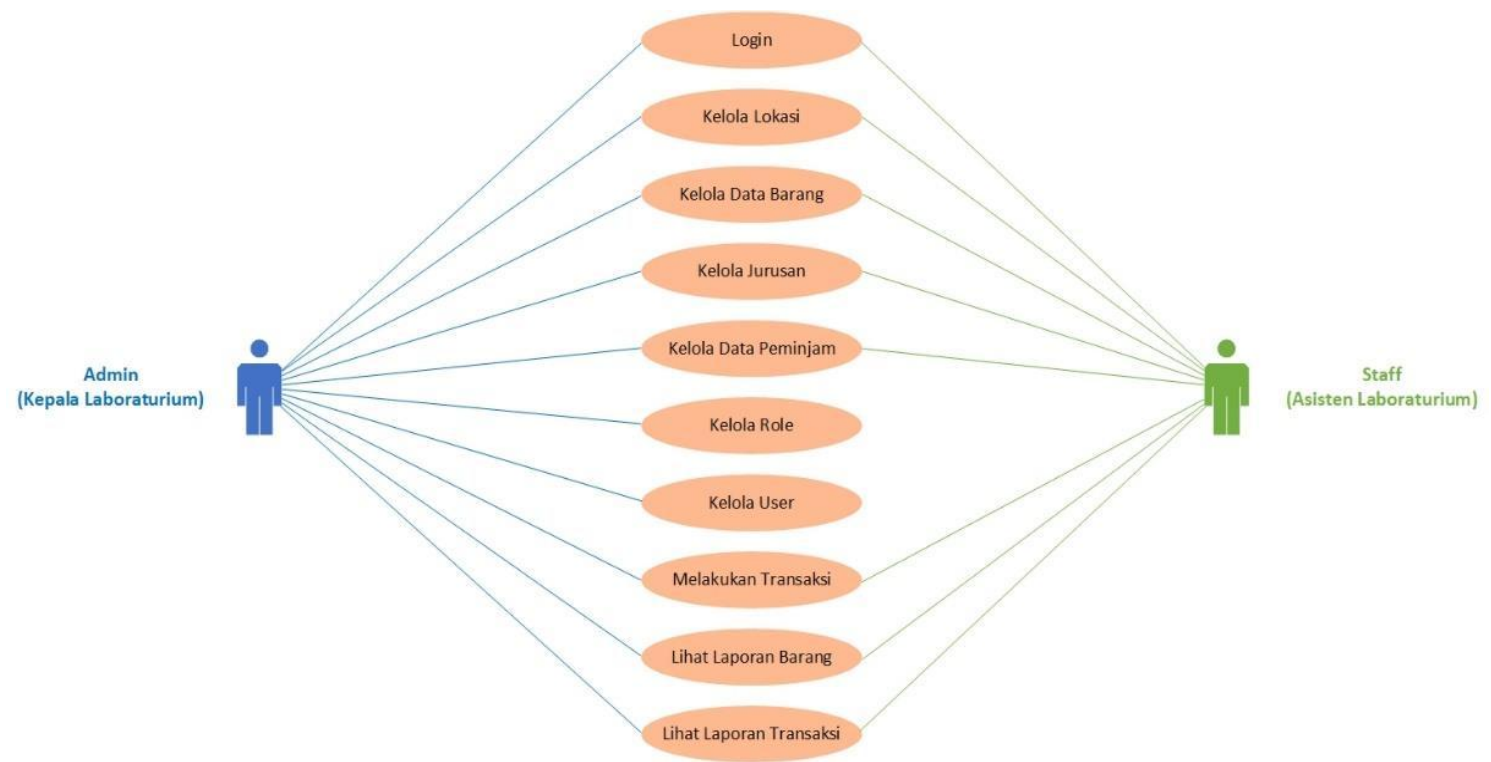

Sumber: Hasil Penelitian (2020)

Gambar 2. Use case diagram keseluruhan

Perangkat lunak minimum yang diperlukan di dalam sistem aplikasi yang dibuat adalah: Sistem Operasi Berbasis Windows, Linux, Text Editor Sublime Text atau Visual Studio Code, MySQL Database Server, Web Server Apache, PHP Versi 7, Web Browser Google Chorme, Firefox, dan lain sebagainya.

Workshop Desain RAD, desain sistem mulai membuat: 1) desain proses (usecase, scenario, activity diagram), 2) desain database, dan 3) desain user interface. Rancangan dengan menggambarkan tentang cara user berkomunikasi dengan sistem informasi mengenai manajeman pada aset laboratorium komputer. Pada use case terdapat 2 (dua) aktor yaitu Kepala Laboratorium selaku Admin dan Asisten Laboratorium dengan role yang berbeda untuk Admin dapat mengakses seluruh menu sedangkan untuk Asisten Laboratorium tidak bisa mengakses kelola role dan user.

Activity diagram login menjelaskan tentang alur dan urutan kegiatan aktor (staff, admin) dan sistem dalam melakukan login ke dalam sistem, dimulai dengan membuka web, hingga 
berhasil masuk kepada dashboard dari aplikasi berbasis web. Berikut merupakan activity diagram login pada gambar 3.

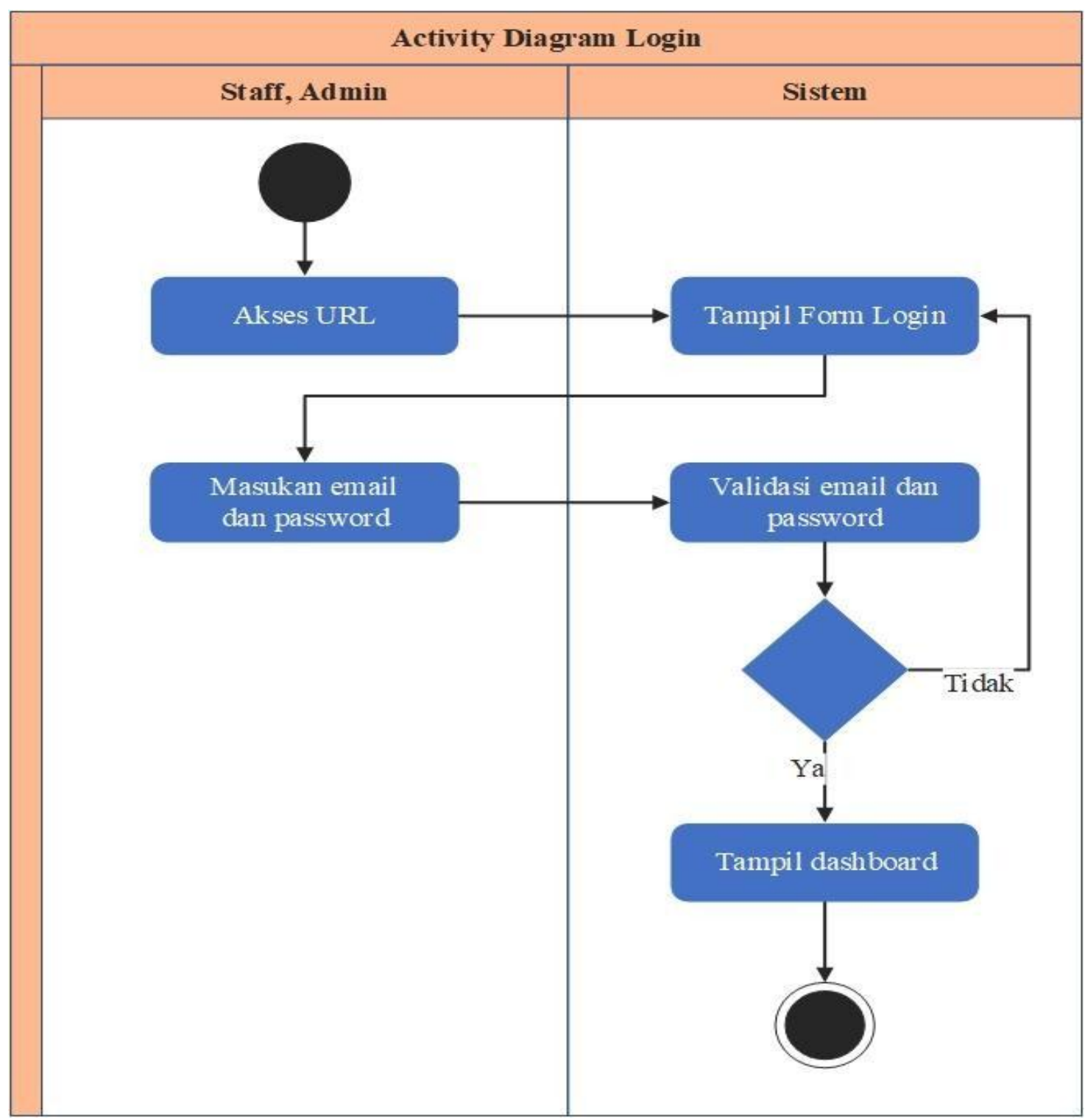

Sumber: Hasil Penelitian (2020)

Gambar 3. Activity Diagram Login

Interaksi antara aktor pengguna, yaitu user dengan use case login dijelaskan dalam use case skenario dalam tabel 2.

Tabel 2. Skenario Use Case Login Semua Aktor

\begin{tabular}{|c|c|}
\hline \multicolumn{2}{|c|}{ Identifikasi } \\
\hline Usecase Name & Login \\
\hline Usecase ID & UCU-1 \\
\hline Aktor & Admin, Staff \\
\hline Description & $\begin{array}{l}\text { Use case menggambarkan aktor dalam mengerjakan } \\
\text { login untuk dapat menampilkan menu utama. }\end{array}$ \\
\hline Triger & Aktor melakukan login. \\
\hline Kondisi awal & Sistem menampilkan form Login \\
\hline \multicolumn{2}{|c|}{ Skenario Utama } \\
\hline Aksi aktor & Reaksi Sistem \\
\hline 1. Aktor mengisi email dan password yang kosong & \\
\hline 2. Aktor menekan tombol login & 3. Sistem melakukan vadisasi login berdasarkan email \\
\hline
\end{tabular}




\begin{tabular}{|c|c|}
\hline \multicolumn{2}{|c|}{ Identifikasi } \\
\hline & dan password yang berada di database \\
\hline & 4. Sistem mengkonfirmasi email dan password \\
\hline & $\begin{array}{l}\text { 5. Sistem menampilkan kesalahan input nama } \\
\text { pengguna dan kata kunci }\end{array}$ \\
\hline \multicolumn{2}{|c|}{ Skenario Alternatif } \\
\hline Aksi Aktor & Reaksi Sistem \\
\hline \multicolumn{2}{|l|}{ password yang benar } \\
\hline 7. Aktor menekan tombol login & 8. Menampilkan menu utama \\
\hline
\end{tabular}

Sumber: Hasil Penelitian (2020)

Untuk desain databasenya menggunakan gambaran entity relationships diagram (ERD) yaitu terdiri dari 9 entity yang mewakili dari 9 tabel yang akan dibuat dalam sistem ini yang tampil pada gambar 4 .

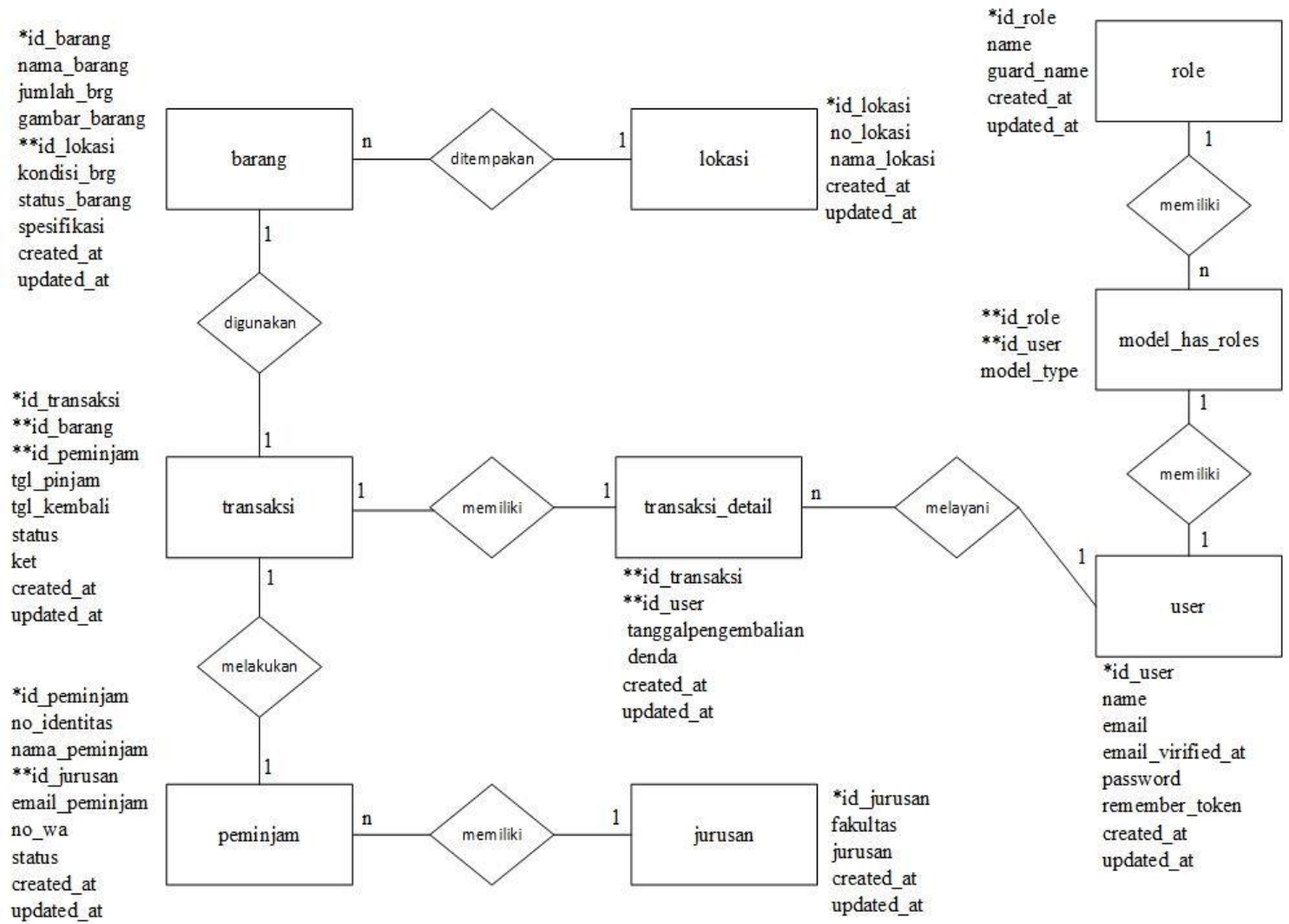

Sumber: Hasil Penelitian (2020)

\section{Gambar 4. Entity Relationship Diagram}

Berikut adalah rancangan spesifikasi data tabel dan dalam penulisan ini yang dicontohkan adalah tabel user dengan sturuktur tabel seperti pada tabel 3.

Tabel 3.Struktur Tabel User

\begin{tabular}{clcccc}
\hline No & Elemen Data & Nama Kolom & Tipe Data & Lebar & Keterangan \\
\hline 1 & Id user & id_user & bigint & 20 & Primary key \\
\hline 2 & Nama User & nama_user & varchar & 255 & \\
\hline 3 & Email Login & email & varchar & 255 & \\
\hline 4 & Waktu Verifikasi & email_virified_at & timestamp & & \\
& Email & & & & \\
\hline 5 & Password & password & varchar & 255 & \\
\hline
\end{tabular}




\begin{tabular}{clcccc}
\hline No & Elemen Data & Nama Kolom & Tipe Data & Lebar & Keterangan \\
\hline 6 & Token Pengingat & remember_token & varchar & 100 & \\
\hline 7 & Tanggal dibuat & created_at & timestamp & & \\
\hline 8 & Tanggal diubah & updated_at & timestamp & & \\
\hline
\end{tabular}

Sumber: Hasil Penelitian (2020)

Perancangan user interface atau antarmuka sebagai rujukan implementasi tampilan program. Perancangan user interface atau antarmuka halaman login terdapat input email dan password dan tombol login yang digunakan untuk masuk ke sistematis seperti pada gambar 5 berikut:

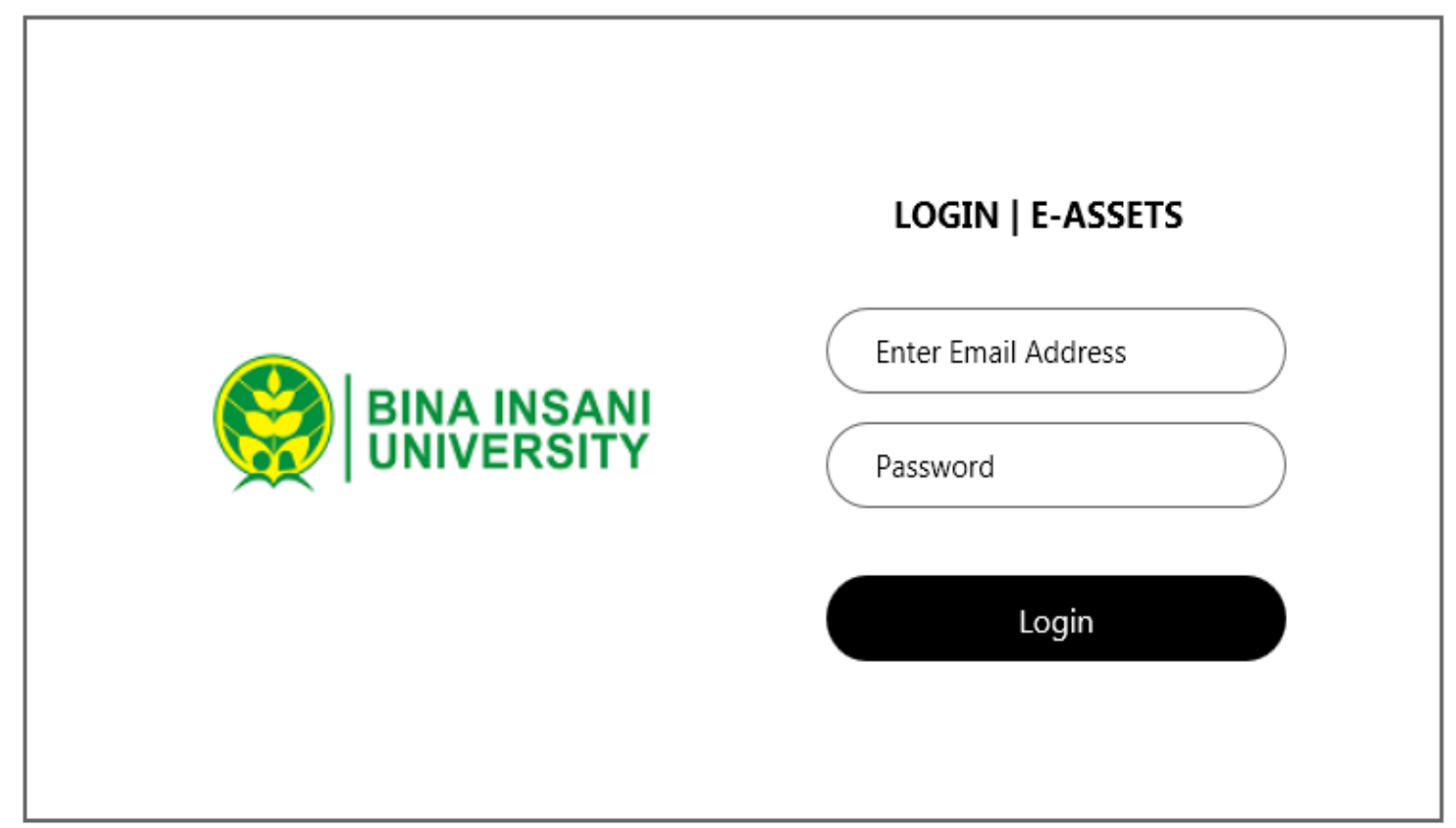

Sumber: Hasil Penelitian (2020)

Gambar 5. Interface Halaman Login

Implementation, pembangunan sistem dengan melakukan coding untuk membuat sistem ini untuk manajemen mengenai aset pada laboratorium komputer, dan mengerjakan pengujian pada sistem dengan melibatkan kepala lab. Universitas Bina Insani memberikan tanggapan terkait aplikasi tersebut dalam tabel 4.

Tabel 4. System Testing

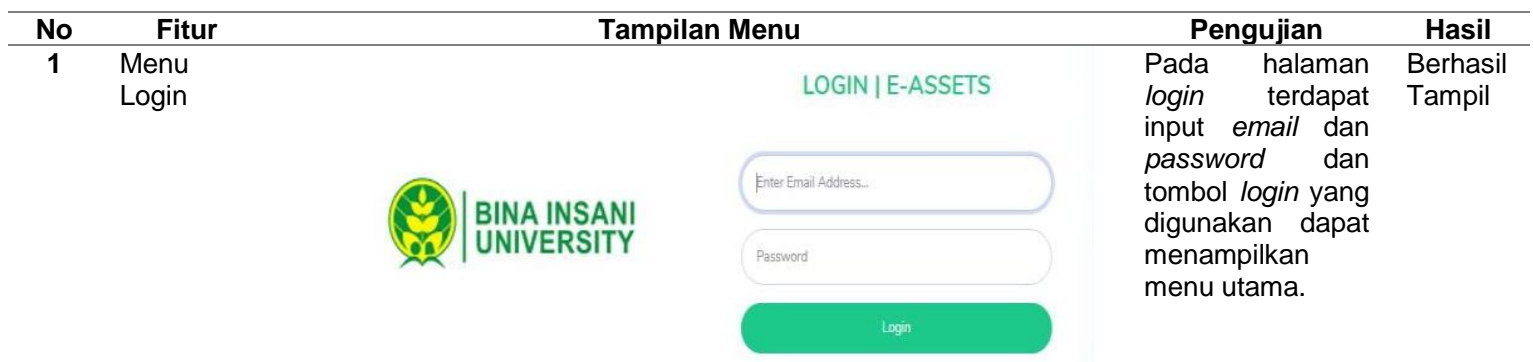




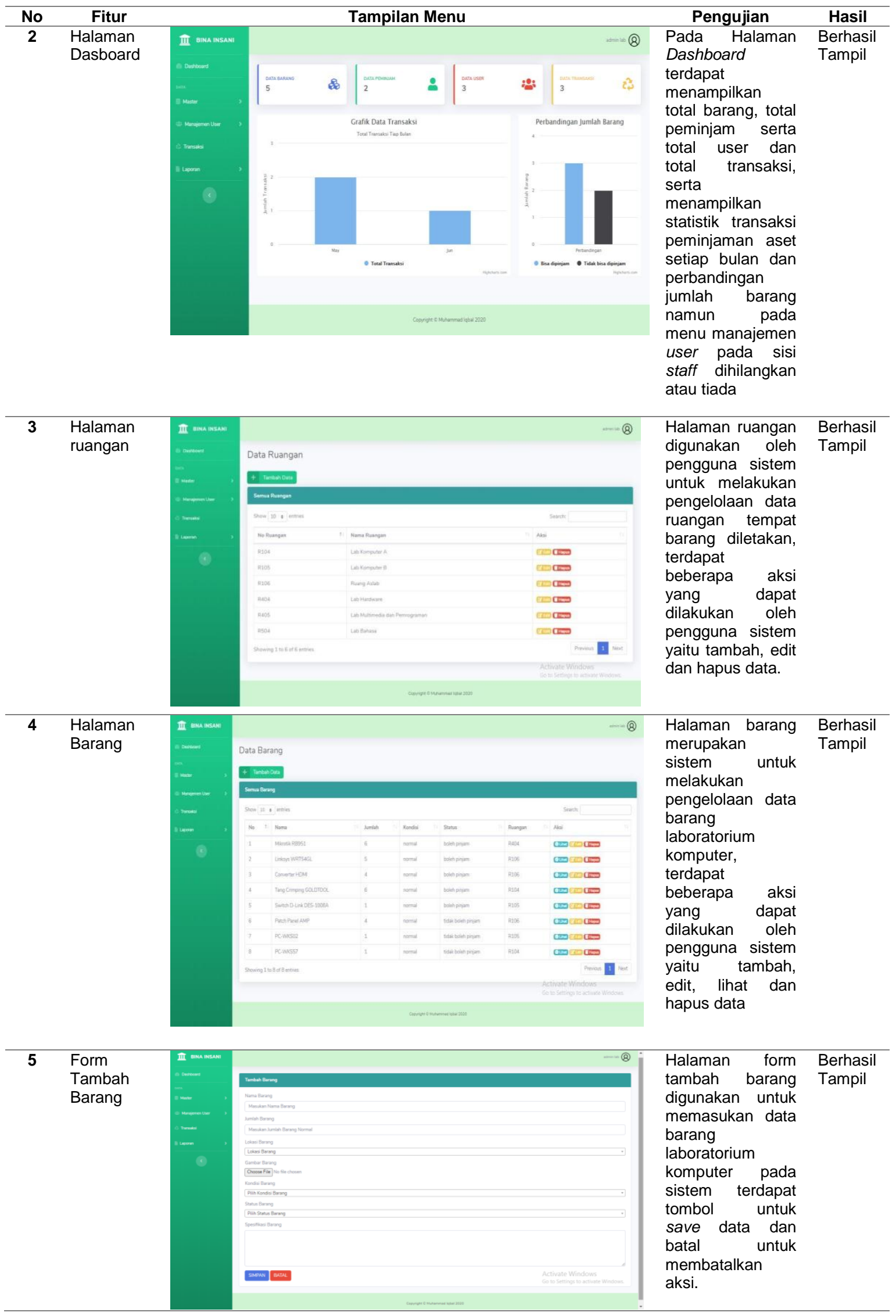


BINA INSANI ICT JOURNAL ISSN: 2355-3421 (Print) ISSN: 2527-9777 (Online); 187 - 197

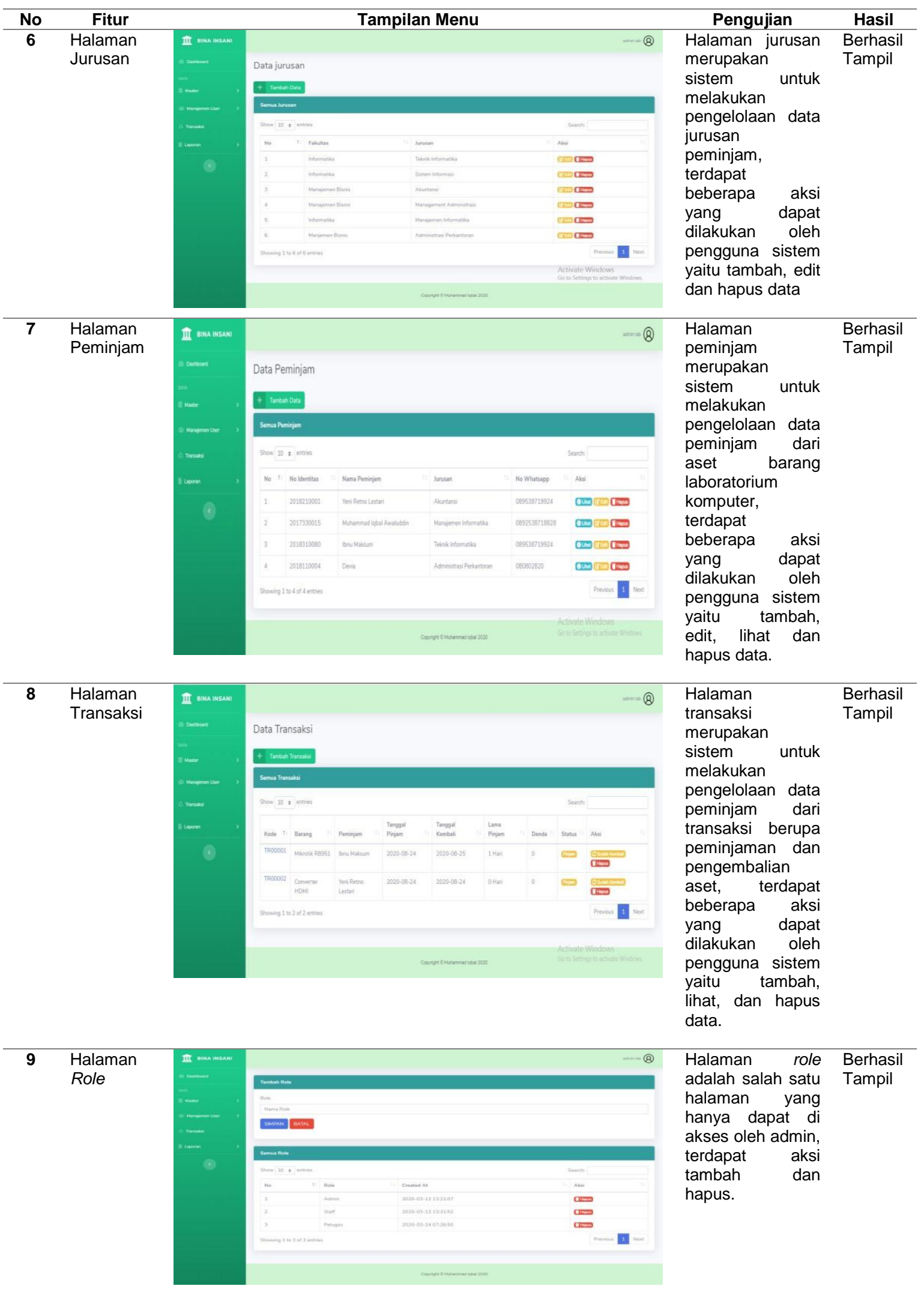




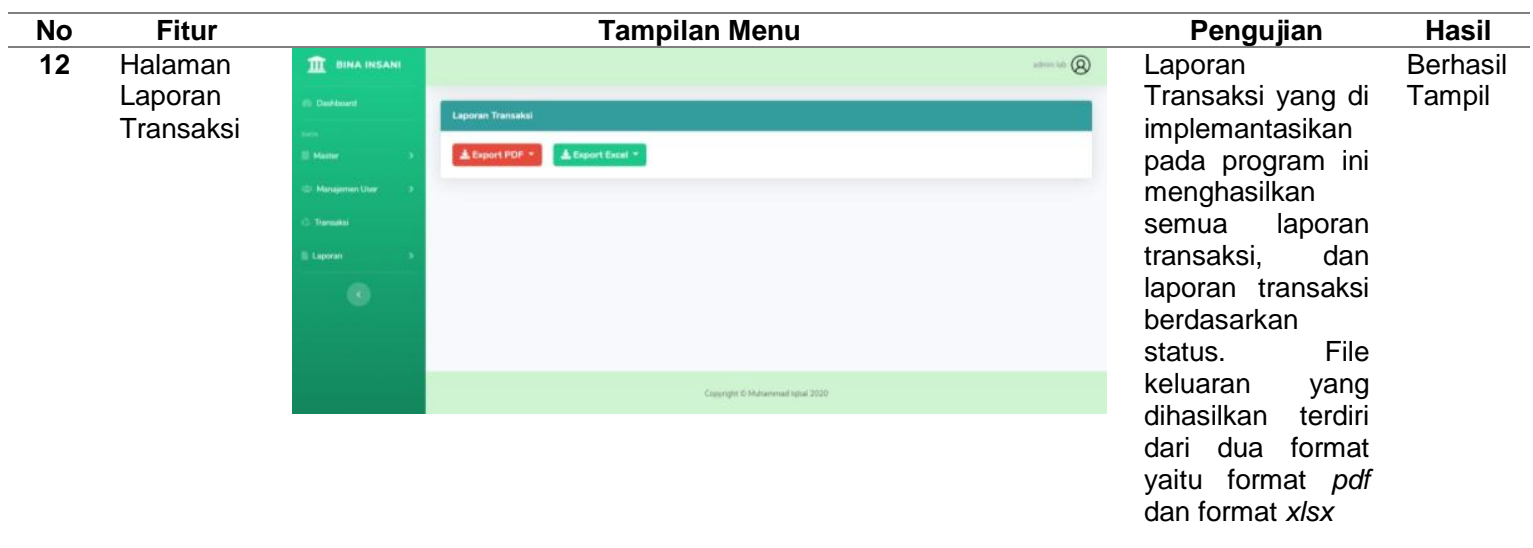

Sumber: Hasil Penelitian (2020)

\section{Kesimpulan}

Kesimpulan yang diperoleh dari kegiatan penelitian ini adalah: 1) Dengan adanya sistem informasi dalam pengelolaan untuk aset berbasis web dapat memberikan informasi antara jumlah barang yang berada pada laboratorium dengan catatan yang tersimpan yang akan lebih akurat, 2) Dengan diterapkannya aplikasi ini proses pencatatan akan menjadi rapih dan mengurangi terjadinya kehilangan data karena data tersimpan dalam bentuk file, 3) Dengan memanfaatkan aplikasi ini proses untuk mencari data akan jauh lebih berkualitas dikarenakan data-data dapat dicari dalam satu aplikasi, dan 4) Dengan pemanfaatan framework laravel dapat memudahkan bagi admin dalam mengelola aplikasi dengan mudah karena struktur dibangun dengan pemisahan MVC serta mempermudah pembuatan laporan yang terkait tentang pengelolaan aset pada laboratorium komputer harapannya penelitian selanjutnya dapat dilakukan pengembangan sistem yaitu sistem dapat meminjam lebih dari 1 barang dan pelaporan data ditambah berdasarkan periode atau waktu dan mengembangkannya kepada sistem android atau IOS.

\section{Ucapan Terima Kasih}

Peneliti mengucapkan banyak terimakasih kepada Universitas Bina Insani yang telah memberikan dukungan selama berjalannya kegiatan penelitian.

\section{Referensi}

[1] S. Suryaningsih, "Pengembangan Sistem Pengelolaan Administrasi Laboratorium Fisika UIN Walisongo Semarang Berbasis Web," Pendidikan Fisika Fakultas Sains dan Teknologi Universitas Islam Negeri Walisong Semarang, 2017.

[2] P. Y. Trisnanto and H. Lala, "Perancangan Sistem Informasi Laboratorium Komputer pada Program Studi D-III PMK Poltekkes Kemenkes Malang," J. Pendidik. - Teor. Penelitian, dan Pengemb., vol. 1, no. 11, pp. 2152-2157, 2016.

[3] E. Y. Anggraeni and R. Irviani, "Pengantar Sistem Informasi," Kesatu, Yogyakarta: CV Andi Offset, 2017.

[4] W. J. Kurniawan, "Sistem Informasi Pengelolaan Laboratorium Komputer UPI-YPTK Padang," J. Edik Inform., vol. 2, no. 1, pp. 95-101, 2015.

[5] S. Pastima and A. Kasnady, "Analisis Model View Controller (MVC) Pada Bahasa Php," J. ISD, vol. 2, no. 2, pp. 56-66, 2016.

[6] K. Wijaya and A. Christian, "Implementasi Metode Model View Controller (MVC) Dalam Rancang Bangun Website SMK Yayasan Bakti Prabumulih," Paradig. - J. Komput. dan Inform., vol. 21, no. 1, pp. 95-102, 2019.

[7] A. Kartubi and R. W. Arifin, "Sistem Informasi Perpustakaan Berbasis Website Dengan Framework Laravel," J. Mhs. Bina Insa., vol. 3, no. 2, pp. 213-222, 2019.

[8] D. Setiyadi, Sistem Basis Data Dan SQL. Jakarta: Mitra Wacana Media, 2020.

[9] E. Yanuarti, "Desain Aplikasi Pengelolaan Laboratorium Komputer," J. Sisfokom (Sistem Inf. dan Komputer), vol. 6, no. 1, p. 60-66, 2017.

[10] E. K. Kenneth and E. K. Julie, "Analisis dan Perancangan Sistem," 2010. 
[11] A. Rini and Fatmariani, "Penerapan Metode RAD Pada Sistem Pengajuan Pengambilan Data Penelitian Bankesbangpol Kota Palembang," J. TI Atma Luhur, vol. 4, no. 1, pp. 1-12, 2017.

[12] M. P. Puteri and H. Effendi, "Implementasi Metode RAD Pada Website Service Guide 'Tour Waterfall South Sumatera,"' J. Sisfokom (Sistem Inf. dan Komputer), vol. 7, no. 2, p. 130136, 2018. 